
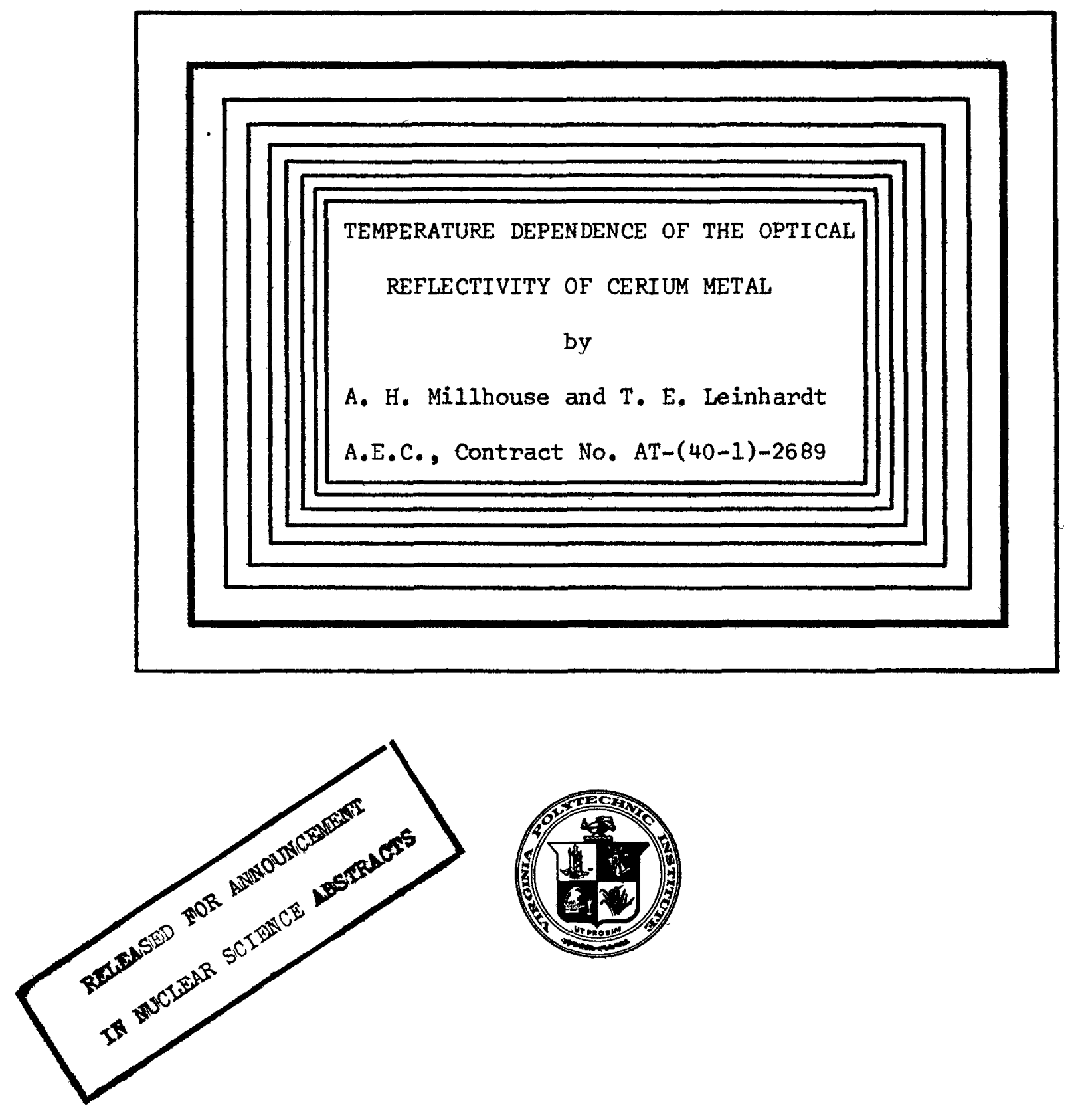

DEPARTMENT OF PHYSICS

VIRGINIA POLYTECHNIC INSTITUTE

BLACKSBURG, VIRGINIA 


\title{
TEMPERATURE DEPENDENCE OF THE OPTICAL REFLECTIVITY OF CERIUM METAL
}

\author{
by \\ A. H. Millhouse and T. E. Leinhardt \\ Report to A.E.C., Contract No. AT-(40-1)-2689 \\ August 31, 1965
}

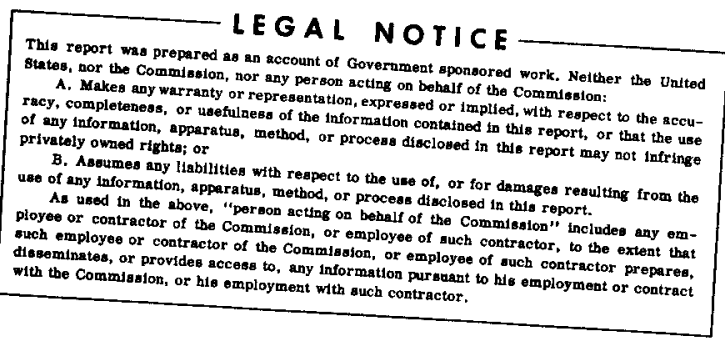




\section{DISCLAIMER}

This report was prepared as an account of work sponsored by an agency of the United States Government. Neither the United States Government nor any agency Thereof, nor any of their employees, makes any warranty, express or implied, or assumes any legal liability or responsibility for the accuracy, completeness, or usefulness of any information, apparatus, product, or process disclosed, or represents that its use would not infringe privately owned rights. Reference herein to any specific commercial product, process, or service by trade name, trademark, manufacturer, or otherwise does not necessarily constitute or imply its endorsement, recommendation, or favoring by the United States Government or any agency thereof. The views and opinions of authors expressed herein do not necessarily state or reflect those of the United States Government or any agency thereof. 


\section{DISCLAIMER}

Portions of this document may be illegible in electronic image products. Images are produced from the best available original document. 


\section{ABSTRACT}

The optical reflectivity of polished, vacuum-annealed samples of Johnson-Matthey cerium has been examined at $300^{\circ}$ and $80^{\circ} \mathrm{K}$. The specimens were mounted in an evacuated opt1cal cryostat. All measurements were made with monochromatic light incident upon the plane surfaces of the samples at an angle of $45^{\circ}$. The source of the radiation was a modIfled Bausch \& Lomb grating monochrometer. Type IP28 photomultipliers were used as detectors. Results indicate that there 18 a decrease in the ratio of the reflectivity at $80^{\circ} \mathrm{K}$ over that at $300^{\circ} \mathrm{K}$ in the 4000 - to $6000-\&$ region. In one specimen, this amounted to about a $20 \%$ change. Below $4000 \&$, the ratio increases rapidly as shorter wavelengths are approached. 
TABLE OF CONTENTS

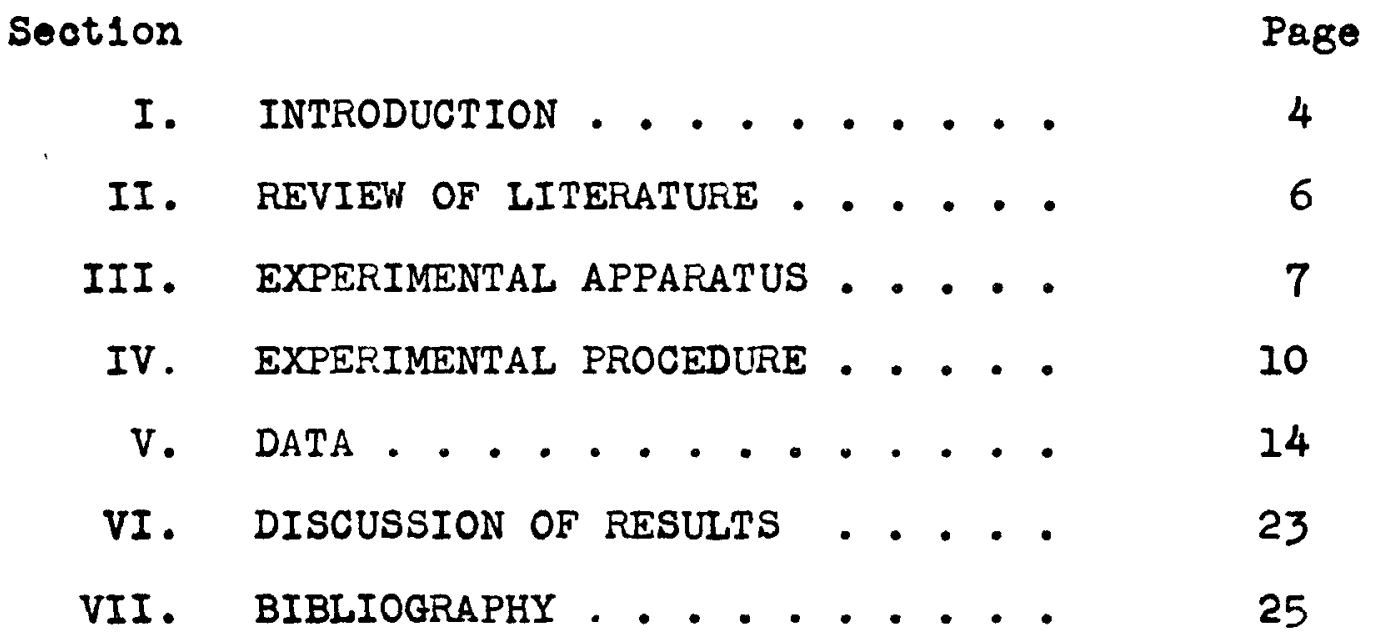




\section{LIST OF FIGURES}

F1gure

Page

1. Cross Seotional View of Cryostat..... 8

2. Simplified Diagram of Experimental Setup . 11

3. Results of Run \#1. . . . . . . . . 17

4. Results of Run \#2.......... 18

5. Results of Run \#2 (continued)...... 19

6. Results of Run \#3........... 20

7. Results of Run \#3 (cont1nued)....... 21

8. Results of Run \#4. . . . . . . . . 22 
INTRODUCTION

When certum specimens are cooled a rapld decrease in resistivity is observed beglnning at a temperature between $100^{\circ} \mathrm{K}$ and $120^{\circ} \mathrm{K}$. This decrease has been attributed to a transition from the normal f.c.c. structure $(\gamma$ cerium, lattice constant $a=5.14 \mathrm{~A}$ ) to a collapsed f.c.c. form $(\alpha$ cerlum, lattice constant $a=4.84 \mathrm{~A}$ ) resulting from a 41, 5d electron transition. 1

In addition to $\gamma$ and $\alpha$ cerlum it has been found that a third allotropic form of cerium exists. ${ }^{2}$ This is a hexagonal close-packed phase with $a=3.68 \mathrm{~A}$ and $c=11.92 \mathrm{~A}$ which is called $\beta$ cerlum. The crystal structure of the metal depends on 1ts temperature and past history. 3,4 $X$-ray studies on a sample out from the same block of cerlum as the one used in this experiment and annealed the same way showed the following percents of the three orystallogranhic phases present: 5
$T\left({ }^{0} \mathrm{X}\right)$
$\gamma(\%)$
$\beta(\%)$
$\alpha(\not)$

(I) 300

90

10

0

(II)

85

80

20

0

(III)

300

80

20

0

(IV)

85

60

30

10 
The purpose of this experiment was to ascertain what effect, if any, these transitions would have on the reflectivity of the metal in the visible and near ultraviolet part of the spectrum. 
The published 11terature on the opt1cal properties of rare earth metals is sparse. Wilburn ${ }^{6}$ has reported on the infrared reflectance of several rare earth elements, but not of cerlum.

A comprehensive article on the experimental work done on the optical properties of metals prior to 1957 has been written by L. G. Schulz ${ }^{7}$ and articles on the theory have been written by several authors. $8,9,10$

A review of work done on the rare earths before 1961 1s provided by Spedding and Daane. 11 
III

EXPERINENTAL APPARATUS

The sample was mounted in a liquid air cryostat containing two quartz windows ( 1 inch diameter, $1 / 16$ inch thick) mounted $90^{\circ}$ apart. A cutaway view of the cryostat and sample mount is shown in flgure 1 . A copper-constantan thermocouple was connected to the sample in the cryostat to monitor its temperature during the experiment.

A Bausch and Lomb Grating Monochromator (Cat. No. 33-86-40-01) was used as a source of monochromat 1c l1ght. This instrument has a focal length of 250 millimeters and a ruled grating area of $50 \times 50$ millimeters. The grating has 600 grooves $/ \mathrm{mm}$, and a blaze angle of $5^{\circ} 10^{\prime}$. The reciprocal linear dispersion is 6.6 millimicrons per millimeter in the first order. As recelved from the factory the monochromator has a hand operated wavelength drum which is mechanically coupled to the grating. Wavelengths can be read from this drum to the nearest millimicron. A motor was added to the monochromator to rotate the drum continuously at a rete of 41.2 degrees/minute (22.8 millimicrons/minute). The monoohromator has adJustable entrance and exit slits which were set at approximately 0.1 millimeter during the whole experiment. 


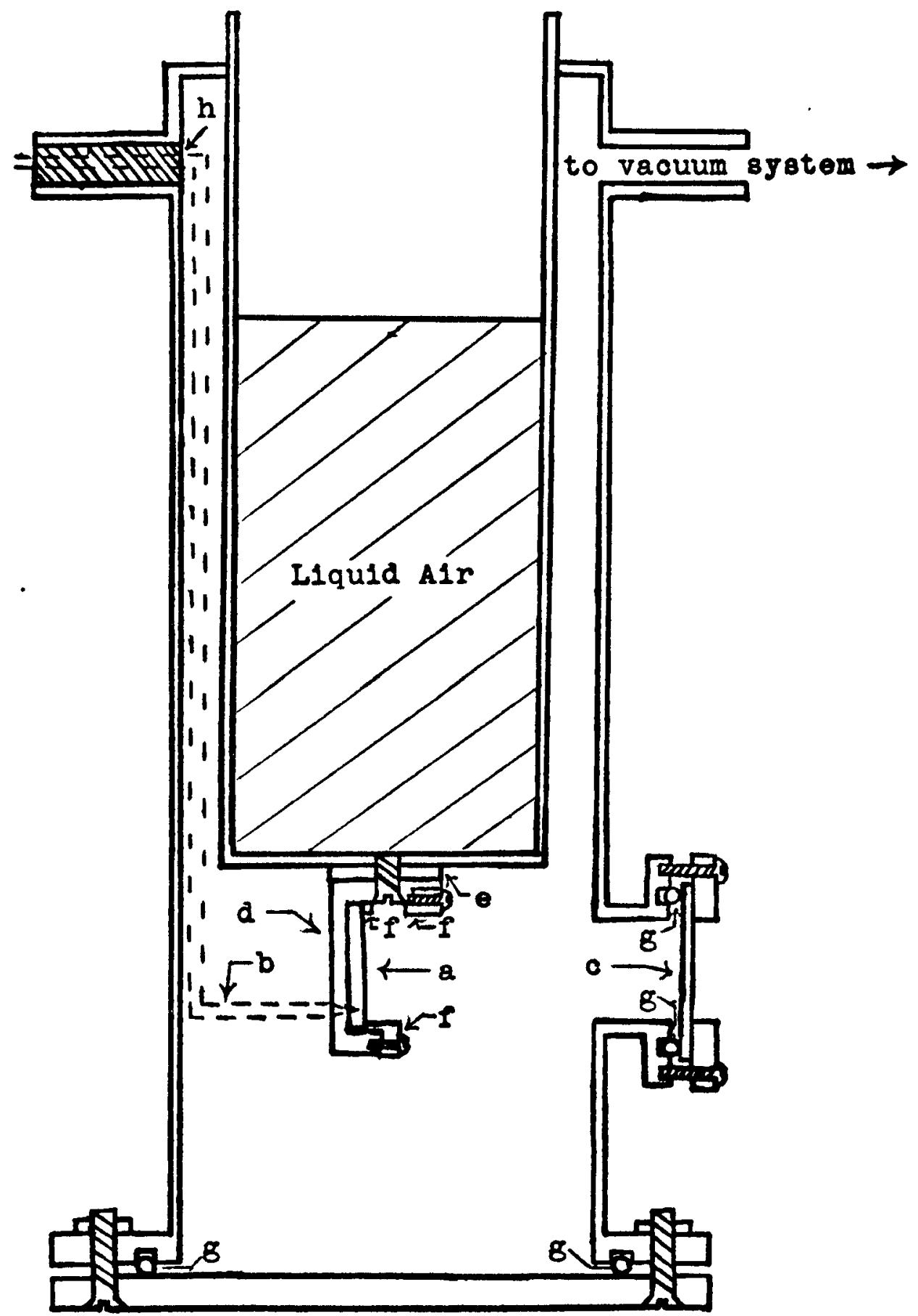

Figure 1. Cross seotional view of cryostat showlng sample (a), oopper constantan thermocouple (b), quartz window $(a)$, sample mount (d), lead washer (e), polyethylene clamps ( $f$ ), o-rings (B), and wax seal (h). 
The light sources used in congunction with the monoohromator were a tungsten fllament bulb (G. E. $18 \mathrm{~A} / \mathrm{T} 10 /$ IP-6V) and a meroury vapor lamp (G.E. Hanovia serlal 38072 Type $\mathrm{S} \mathrm{H}$ ).

Two Amphenol 1P28 photomult1plier tubes were used as radiation detectors. The output of these tubes was recorded on a Varien Model $a-10$ Graphic Recorder and a Varian Model G - 14 Graphio Recorder.

The cryostat was evacuated by means of an oll diffusion pumping system to prevent oxidation of the sample. This system was not equipped with a cold trap. Previous measurements, both with and without a cold trap, showed that use of a cold trap produced no slgnificant change in the data. An optloal lever arrangement with a mirror mounted in the same position as the sample, shown in figure 1, indicated that the rotation of the sample about the axis of the sample holder, due to ejoling between $300^{\circ} \mathrm{K}$ and $80^{\circ} \mathrm{K}$, was less than 0.001 radian. 


\section{EXPERIMENTAL PROCEDURE}

The cerlum sample was cut from a 100 gram block of the metal obtained from Johnson, Matthey \& Company Limited, and labelled by them as batch number m63. The speclmen dimensions were approximately $2.60 \mathrm{~cm} \times 1.70 \mathrm{~cm} \times 0.20 \mathrm{~cm}$ with a mass of 5.39 erams.

Before each run the speoimen was pre-polished using silicon carbide paper, number 320-A, with glycerine as a lubricant until a smooth average surface was obtained. The surface was then oleaned using acetone and methyl alcohol, After cleaning the surface the specimen wa annealed in a vacuum ( $<10 \mathrm{micron}$ of $\mathrm{Hg}$ ) at a temperature of approximately $700^{\circ} \mathrm{F}$ for at least 3 hours. During annealing the specimen was contained in a tantalum boat to prevent contact between the sample and the hot pyrex annealing tube. After annealIng, the specimen was pollshed lightly as before to remove the thin film of oxide on 1ts surface due to the annealing process. The sample was then mounted in the I1quid air cryostat as shown in figure 1.

A simplified diagram of the experimental setup is shown in flgure 2.

After the sample was mounted in the cryostat it was positioned to recelve the inoldent radiation at an inoldence 


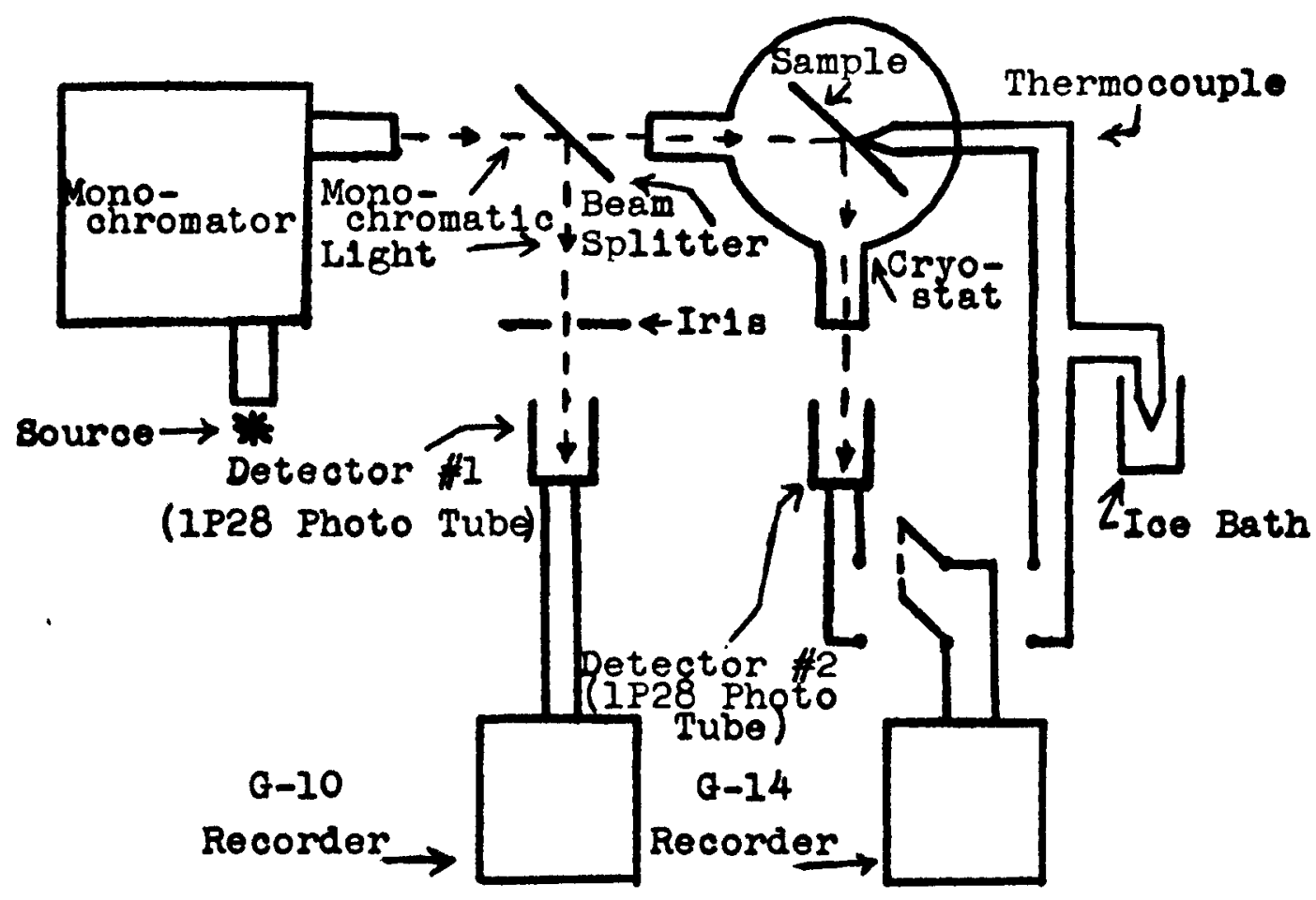

P1gure 2. Blmplified diagram of experimentel setup. 
angle of $45^{\circ}$. The sample chamber was then sealed and connected to the o1l diffusion pumping system.

A beam splitter was used to divide the beam into two parts one of which was monltored directly by a photomultiplier tube (detector \#1), the other part was monitored by a second photomultiplier tube (detector $\# 2$ ) after being refleoted from the sample. A quartz beam splitter was used with the meroury vapor lamp and a glass beam splitter with the tungsten fllament bulb.

The output of detector \#1 was recorded on the G-10 recorder and that of detector \#2 on the $6-14$ recorder. A switoh was used so that the thermocouple output could also be recorded on the G-14 recorder. Both recorders were used on the 10 millivolt full scale setting (2 millivolts per inch).

After the specimen was mounted and the cryostat evacuated, the apparatus assembly was sealed to ellminate background radiation. The wavelength drum was positioned in the wavelength range to be used until maximum deflection on the recorders was obtained. The iris between the beam splitter and detector \#1 was then adjusted unt1l the deflections on the recorders were about the same. The wavelength drum was then connected to the motor drive and turned continuously through the wavelength range of interest wh1le records of the output of deteotors \#1 and \#2 were made. 
A quantity proportional to the reflectivity at temperature $T\left({ }^{\circ} \mathrm{K}\right)$, denoted by $R_{T}$, was obtained by dividing the output of detector \#2 $\left(R_{2}\right)$ by the output of detector \#1 $\left(R_{1}\right)$ at a particular wavelength, 1. e., $\quad R_{T}=R_{2} / R_{1}$ In order to ensure that the proportionality constant between $R_{T}$ and the reflectivity was independent of wavelength the two paths taken by the monochromatic light, shown in figure 2, were made optically 1dentical by the introduction of two quartz windows between the beam splitter and detector \#1. Also, runs were made which showed that $R_{\mathrm{T}}$ did not change appreclably when detectors \#1 and \#2 were interohanged. 
DATA

The data obtained is shown in figures 1 to 8 , inclusive. Each curve in the graphs of $R_{T} 18$ an average of six sets of data and the maximum spread of the data is shown by the error bar in each flgure. The time required to obtain the data for determining $\mathrm{R}_{\mathrm{T}}$ at each temperature was approximately one hour. The time required to $c 001$ the specimen from $300^{\circ} \mathrm{K}$ to $80^{\circ} \mathrm{K}$ was approximately 30 minutes, and approximately three hours was required for the temperature of the specimen to increase from $80^{\circ} \mathrm{K}$ to $300^{\circ} \mathrm{K}$. All data was taken immediately after the specimen reached the temperature involved.

Run \#1

The results of run \#1 are shown in figure 3. Th1s dats was taken using the previously described cerlum sample, labelled sample J. M. 1-0, and the tungsten fllament source.

Flgure 3 (a) shows $R_{T}$ for a complete cycle of temperature from $300^{\circ} \mathrm{K}$ to $80^{\circ} \mathrm{K}$ and back to $300^{\circ} \mathrm{K}$. The order in which the data was taken is shown in the upper right hand corner of this figure.

Figure 3 (b) shows the rat10 $\mathrm{R}_{80}{ }^{\circ} \mathrm{K} / \mathrm{R}_{300}{ }_{\mathrm{K}}$ for the bottom two curves $(\square / 0)$ of figure $3(a)$. This figure shows that the reflectivity of the sample decreases when it is cooled to $80^{\circ} \mathrm{K}$, the decrease varying from about $10 \%$ at 0.6 microns to about $25 \%$ at 0.4 miorons. 
Run \#2

The results of this run are shown in figures 4 and 5. The data was taken using sample J. M. 1-0 and the mercury vapor lamp.

Figure 5 shows the ratio $R_{80^{\circ}} / R_{300^{\circ} \mathrm{K}}$ for cycle $I$ (figure 4, $\square / 0$ ) and cycle 2 (figure 4, $\nabla / \Delta$ ). The curve for cycle I shows the same decrease as shown in flgure 3 w1th a marked rise as short wavelengths are approached. The rat10 $R_{80}{ }^{\circ} / R_{300}{ }_{K}$ shows a quite different behavior for cyole 2. This is attributed to the change in the fractions of the three crystallograph1c phases present.

Run \#3

The results of run \#3 are shown in figures 6 and 7 . In th1s run sample J. M. $1-0$ and the mercury vapor lamp were used.

Immediately after cooling the specimen to $80^{\circ} \mathrm{K}, R_{T}$ was measured $(\square$, figure 6$)$. The specimen was kept at a temperature of $80^{\circ} \mathrm{K}$ for 3 hours and $R_{T}$ remeasured $(\Delta$, figure 6 ). As shown in figure 6 an 18othermal change in $R_{T}$, at $80^{\circ} \mathrm{K}$, was observed and 18 attributed to an 1sothermal change in crystal structure. Th1s type of change has been observed by others. 5 
Run \#4

The results of run \#4 are shown in figure 8. Th1s run was made using an unannealed aluminum sample whose dimensions and surface preparation were the same as sample J. M. 1-0.

Within the spread of the data there was little change In the reflectivity of the aluminum sample when it was cooled.

Other experimental results ${ }^{12}$ show a much flatter dependence of reflectivity on wavelength than was observed here. This is probably due to the different preparation of the surface. However, the change in reflect1vity due to cooling is in agreement with other experimental results.7 

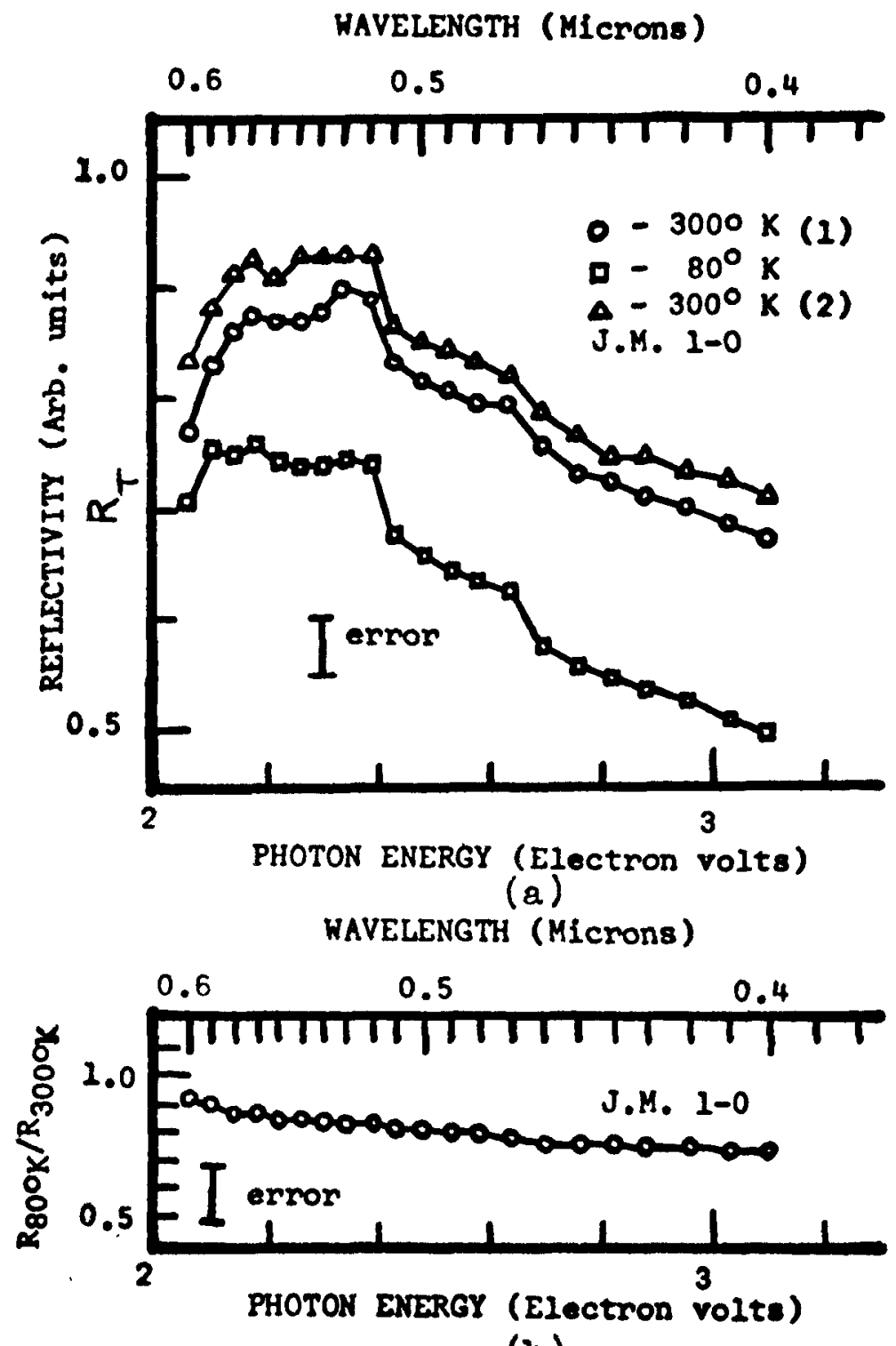

(b)

Figure 3. Results of mun \#1. 


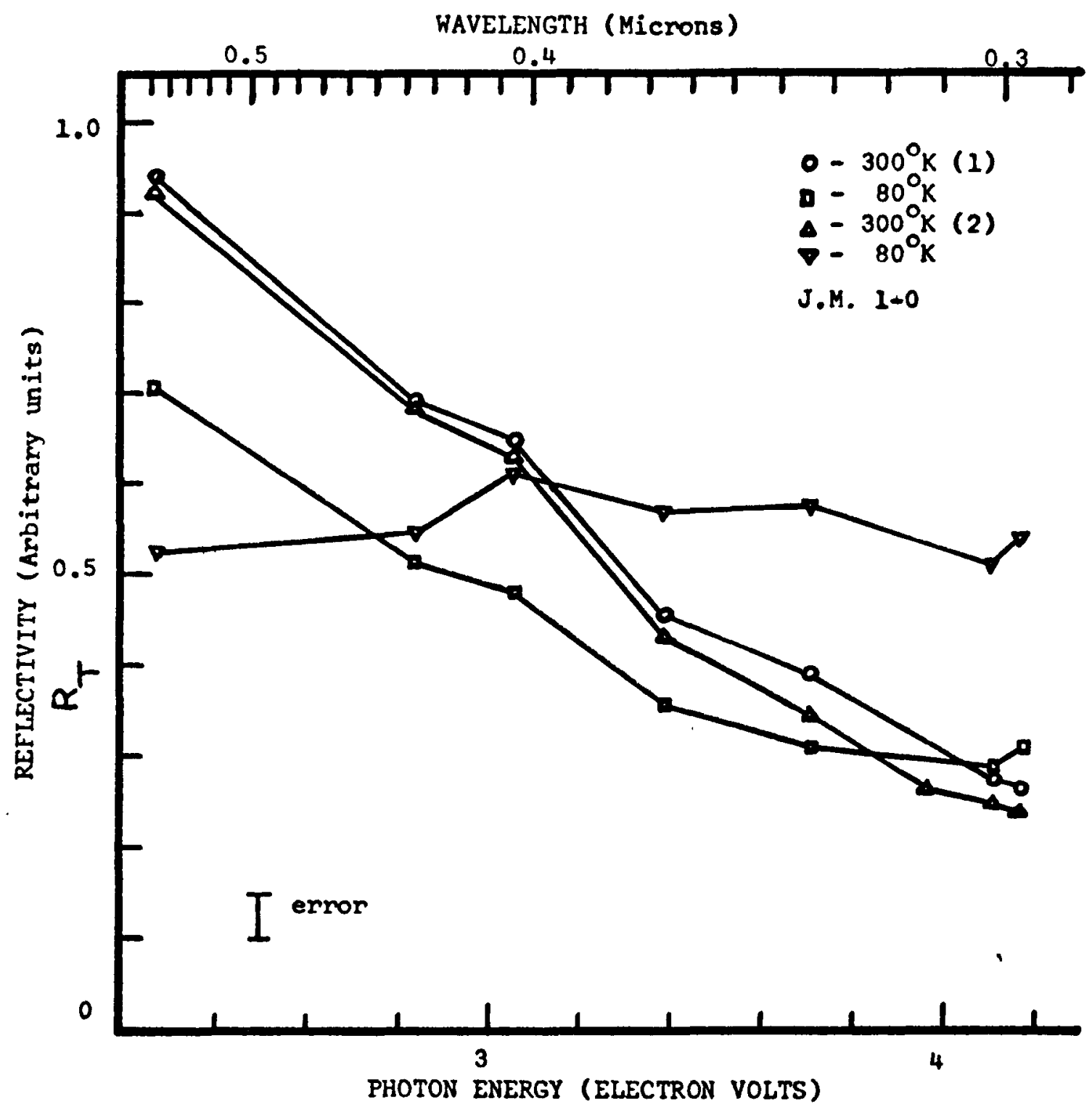

F1gure 4. Results of min \#2. 


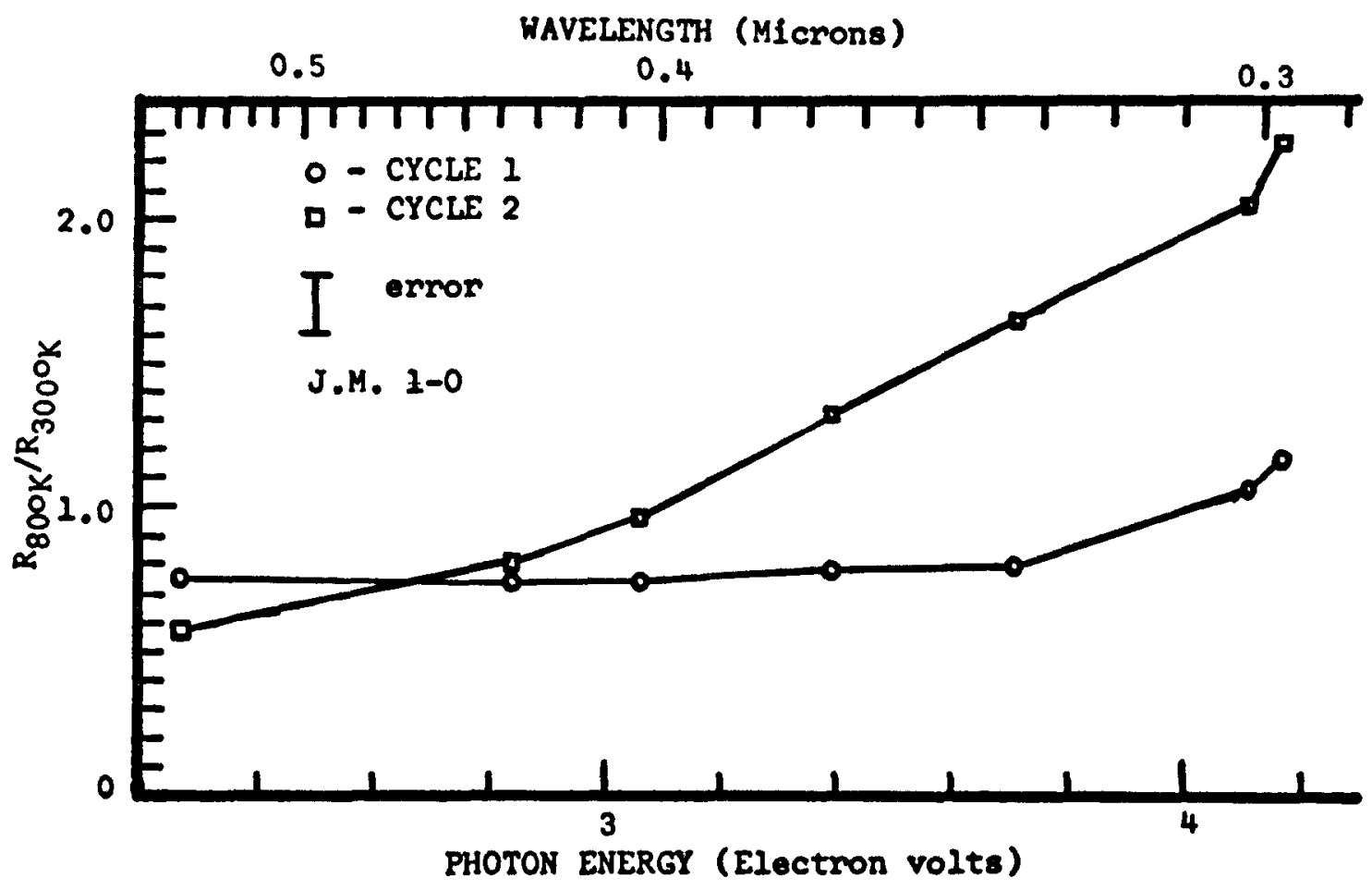

Figure 5. Results of run \#2 (continued). 


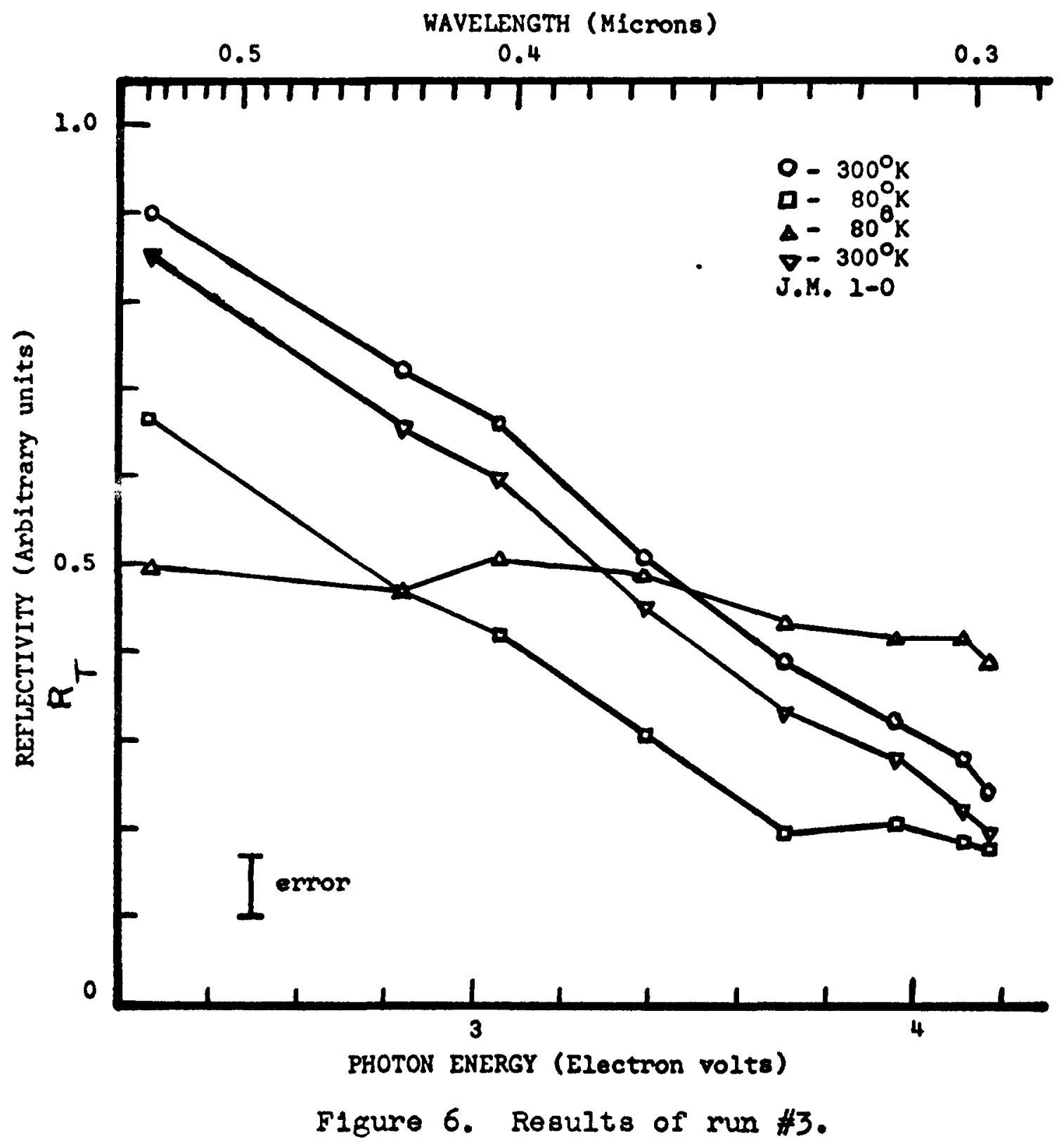




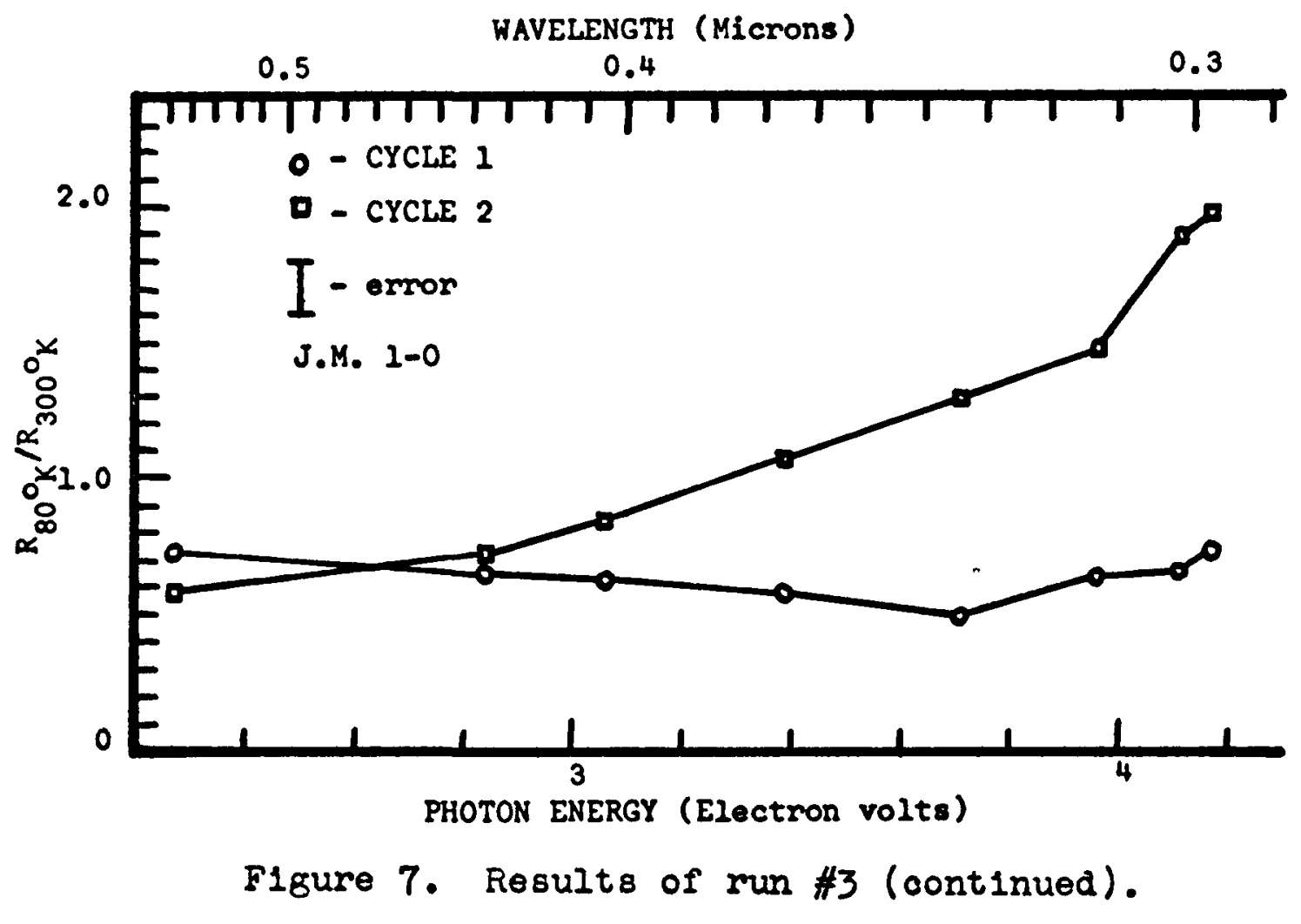




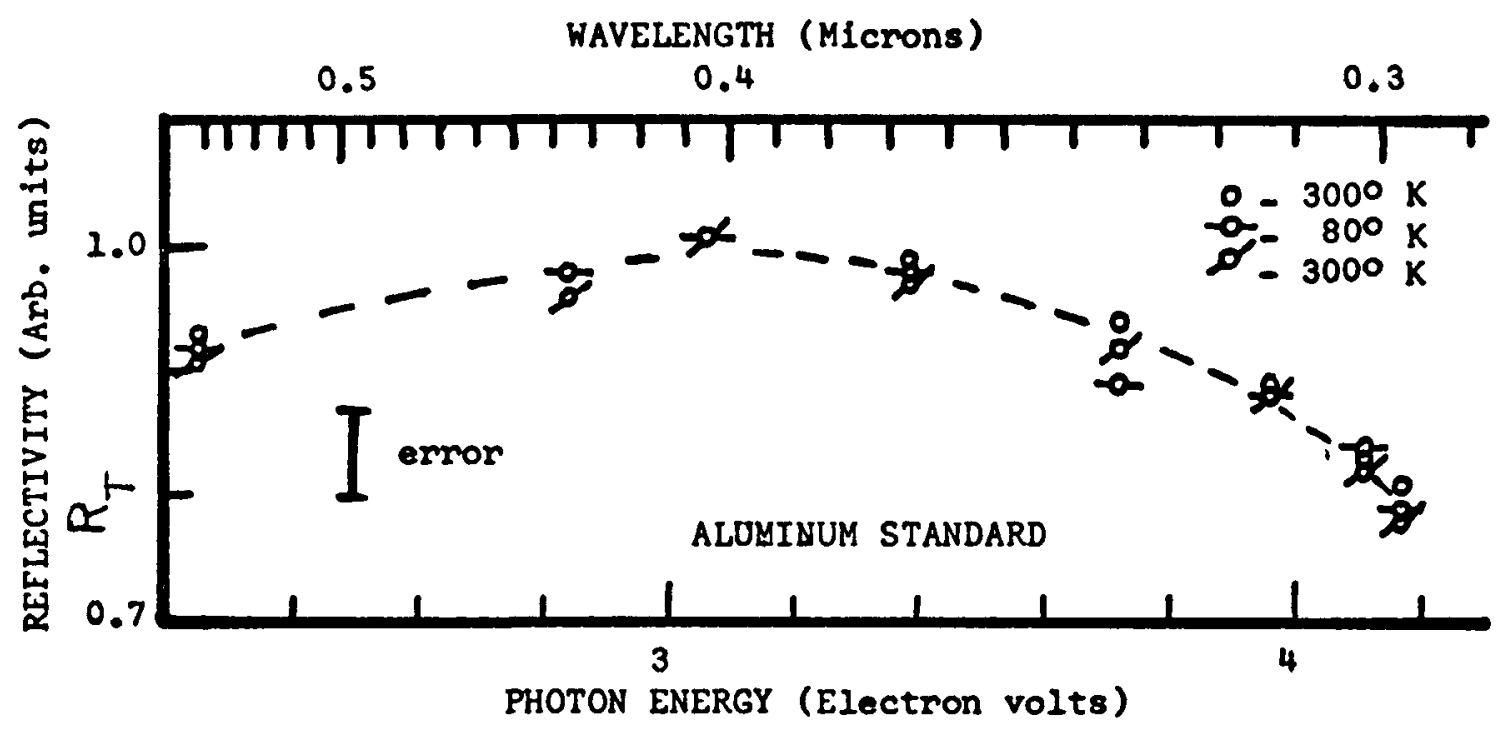

(a)

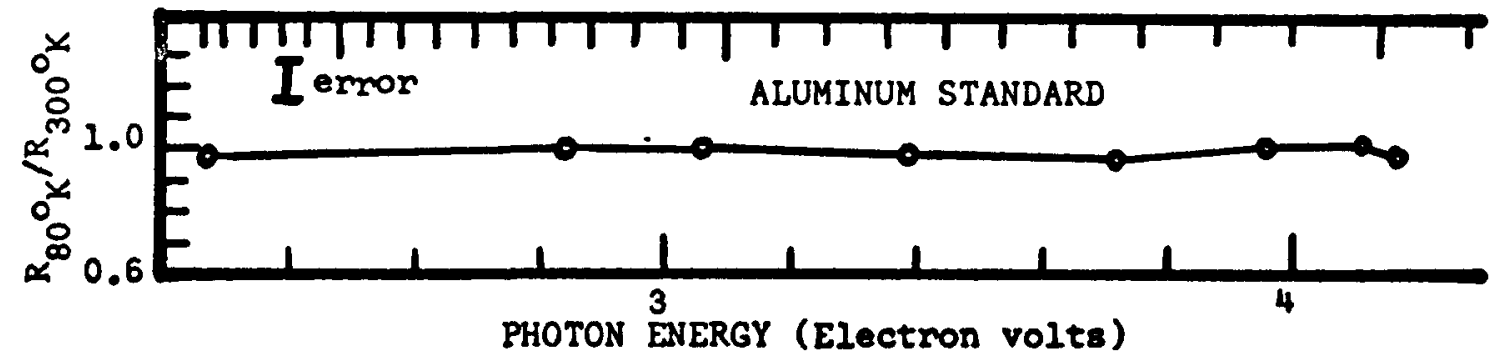

(b)

Figure 8. Results of run \#4. 
VI

DISCUSSION OF RESULTS

The experimental results presented in figures 3 to 7 , inclusive, show a decrease in the reflectivity of the annealed cerlum sample when it is cooled from $300^{\circ} \mathrm{K}$ to $80^{\circ} \mathrm{K}$. Th1s decrease varies from about 10 percent at 0.60 microns to between 25 and 50 percent at 0.33 microns, and below 0.33 microns begins to rise again. The reflectivity changes markedly with continued cycling and in one case an isothermal change was found.

The photoelectric work function of cerlum is 2.84 electron volts. 13 since this energy was in the range of interest in this experiment a measurement of the photoelectric current was made. A probe was introduced into the cryostat at about one centimeter from the face of the polished cerlum sample. The samole chamber was then evacuated and the sample 1lluminated with monochromatic light (mercury vapor bulb) of about the same intensity as that used in the reflectivity measurements. The probe was connected in serles with a 300 volt battery which in turn was connected in serles with a 39 kohm resistor. The other end of the resistor was then connected to the cerlum sample. The voltage drop across the resistor was measured on the G-14 recorder using the 10 m1111volt full scale setting. Although a current of $10^{-7}$ ampere could have been detected by this ciroult, no noticeable 
current was observed when the wavelength of the incident monochromatic light was varied from 0.3 to 0.5 microns.

The basic theory of the optical properties of metals is the Drude free electron theory. $8,9,10$ The mechanism of absorption assumed in this theory is that of conduction electrons, and the success of this theory depends on how strong this mechanism is for the particular metal and wavelength interval of interest.

Other mechanisms that contribute to absorption and cause deviations from the Drude theory are reviewed in an article by Roberts, 14 one of which is the absorption due to internal photoelectric effects or band transitions. These other mechanisms of absorption tend to be strongest toward the ultraviolet and their effects often trail off into the near infrared. 7

Clark ${ }^{15}$ has made calculations using the Drude theory and experimentally determined valencles and conductivity for cerlum. These calculations show a slight increase of the reflectivity, in the visible part of the spectrum, when cerium is cooled from $300^{\circ} \mathrm{K}$ to $80^{\circ} \mathrm{K}$. The observed decrease must be a combination of several mechanisms of absorption. However, since the detalled band structure of cerlum is not known, no quantitative description of the absorption process can be given. 
VII

\section{BIBLIOGRAPHY}

1. James, Legvold, \& Spedding, 'The Resistivity of Lanthanum, Cerium, Praseodymium, and Neodymium at Low Temperatures'

Physical Review

Vol. 88,1092

2. Mc Hargue, Yakel, \& Jetter, Met. Ann. Proz. Rep.,

Oct. 10, 1957, ORNL-2422,

p. 207

3. Gschneidner, K.,

'Phase Transformations in

Metall10 Cerium'

4. Lounasmaa, $0 .$,

'Specific Heat of Cerium and Europium Metals Between 0.4 and $4^{\circ} \mathrm{K}^{\prime}$

Physical Review

V01. 133, A502

5. Major, R. W. \& Leinhardt, T. E., 'Crystal Structure and Resistivity of Cerium as Determined by Temperature' Bulletin of the American Physloal Soolety, Vol. 10, 451 
6. W1lburn, 0.K.,

7. Schulz, L. G.,

8. Seitz, F.,

9. Givens, M.,

10. Stern, F.,
'Some Optical Properties of Several Evaporated Ráre Earth. Metals'

U. S. Army Tank-Automotive Center Report

No. $R R-36$, Detro1t (1961).

'The Experimental Study of the Optical Properties of Metals and the Relation of the Results to the Drude Free Electron Theory' Advances in Physics Vol. 6, No. 21, 102 January (1957)

Modern Theory of Solids, Chapter 17 , Mc Graw-Hill Book Co., Inc. (1940)

'Optical Properties of Metals' Solid State Physics, Vol. 6, p. 313 Academic Press Inc. (1958)

'Elementary Theory of the 
Optical Properties of Solids' Sol1d State Physics,

Vol. 15, p. 299

Academic Press Ino.

11. Speda1ng, F. H. \& Daane, A. H., editors, The Rare Earths, John Wlley \& Sons, Inc.

12. Bennett, H., Silver, M. \& Ashley, E., 'Infrared Reflectance of Aluminum Evaporated in Ultra-High Vacuum' Journal of the Optical Soclety of America

Vol. 53, 1089

13. Hodgeman, C. D., Handbooks of Chemistry and Physics, Chemical Rubber Publishing Co.

14. Roberts, S.,

'Optical Properties of Copper' Physical Review,

Vol. 117, 663

15. Clark, J. G.,

'The Reflectivity of Cerium Metal as a Function of Temperature', M. S. thesis, Virginia Polytechnio Institute (1964) 